\title{
Validity assessment of self-reported medication use for hypertension, diabetes and dyslipidemia in a pharmacoepidemiologic study by comparison with health insurance claims
}

\author{
Minako Matsumoto ( $\nabla$ minako.a7@keio.jp ) \\ Keio University https://orcid.org/0000-0002-7705-9903 \\ Sei Harada \\ Keio Gijuku Daigaku - Shinanomachi Campus \\ Miho lida \\ Keio Gijuku Daigaku - Shinanomachi Campus \\ Suzuka Kato \\ Keio Gijuku Daigaku - Shinanomachi Campus \\ Mizuki Sata \\ Keio Gijuku Daigaku - Shinanomachi Campus \\ Aya Hirata \\ Keio Gijuku Daigaku - Shinanomachi Campus \\ Kazuyo Kuwabara \\ Keio Gijuku Daigaku - Shinanomachi Campus \\ Ayano Takeuchi \\ Keio Gijuku Daigaku - Shinanomachi Campus \\ Daisuke Sugiyama \\ Keio Gijuku Daigaku - Shinanomachi Campus \\ Tomonori Okamura \\ Keio Gijuku Daigaku - Shinanomachi Campus \\ Toru Takebayashi \\ Keio Gijuku Daigaku - Shinanomachi Campus
}

Research article

Keywords: Cohort-study, Health insurance claims, Medicines, Pharmacoepidemiology, Self-report, Validation

Posted Date: January 17th, 2020

DOl: https://doi.org/10.21203/rs.2.21216/v1

License: @ (1) This work is licensed under a Creative Commons Attribution 4.0 International License. Read Full License

Version of Record: A version of this preprint was published at Journal of Epidemiology on January 1st, 2020. See the published version at https://doi.org/10.2188/jea.JE20200089. 


\section{Abstract}

\section{Background}

Although self-reported questionnaires are widely employed in epidemiologic studies, their validity has not been sufficiently assessed. The aim of this study was to evaluate the validity of a self-reported questionnaire on medication use by comparison with health insurance claims and to identify individual determinants of discordance.

\section{Methods}

Participants were 2,720 community-dwellers aged 37 to 78 years from the Tsuruoka Metabolomics Cohort Study. Information on lifestyle and medications was collected through a questionnaire. Sensitivity and specificity were determined using health insurance claims from November 2014 to March 2016, which were used as a standard. Potential determinants of discordance were assessed by multivariable logistic regression.

\section{Results}

The self-reported questionnaire on medication use showed high validity. Sensitivity and specificity were 0.95 (95\% Cl:0.93$0.96)$ and 0.94 (0.93-0.95) for antihypertensives, 0.94 (0.91-0.97) and 0.98 (0.98-0.99) for diabetes medications, 0.84 (0.82$0.87)$ and 0.96 (0.95-0.97) for dyslipidemia medications, respectively. Males without high education were found to be associated with discordant reporting, especially those with medication use for dyslipidemia.

\section{Conclusions}

In this population-based study, we found that the self-reported questionnaire on medication use was a valid measure of true medication use. Sensitivity for dyslipidemia medications was lower than those for the other medications. Type of medication, gender and education influenced discordance in self-reporting.

\section{Background}

The number of patients with three of the major lifestyle-related diseases - hypertension, diabetes and dyslipidemia - is increasing. These are major risk factors for cardiovascular disease [1, 2, 3]. To assess relationships between risk factors and health outcomes in cohort studies, participant characteristics including medication use are often evaluated by self-reported questionnaire. Despite the possibility of information bias, however, the accuracy of self-reported questionnaires has not been sufficiently studied [4,5]. In particular, few reports have explored the individual determinants of discordance between selfreported questionnaires on medication use and the true status of medication.

To date, only a few studies have evaluated the validity of self-reported medication use in population-based studies, and the results of these have been inconsistent $[6,7,8]$. Although self-reported medication use for lifestyle-related disease has shown high validity with sensitivity over $70 \%$, the sensitivity nevertheless varied from study to study. This inconsistency has been explained by differences in data collection method, type of medication and surveyed populations. Moreover, only a few studies have identified individual determinants of discordance between self-reported medication use and true status of medication $[7,9,10]$. These include gender $[7,9]$, age [7, 10], marital status [9], number of medications regularly taken [10], health status [7] and education years [9], albeit that the results varied among studies.

The aim of this study was to evaluate the validity of self-reported medication use for lifestyle-related diseases using health insurance claims as a standard in a population-based cohort study. Individual determinants of discordance, such as social factors, were also examined.

\section{Methods}




\subsection{Japanese healthcare insurance system}

Japan has a universal healthcare insurance system which covers all citizens [11]. There are two types of coverage for individuals aged younger than 75 years, Employees' Health Insurance and National Health Insurance (NHI). The former is managed by the workplace and covers salaried employees while the latter is managed by municipalities and covers individual proprietors, pensioners and those with irregular employment. On reaching 75 years of age, current $\mathrm{NHI}$ members are switched from NHI to Medical Care System for the Advanced Elderly. If an insured member goes to a hospital or pharmacy as an outpatient, their information is stored as health insurance claims data of medical/dental outpatient claims and pharmacy claims.

In Japan, long-term prescriptions are allowed, except for special medications such as newly launched or psychoactive medications; newly launched medications for example can be prescribed in two-week courses. In contrast, most medications, particularly those for lifestyle-related diseases, are prescribed in courses of 90 days duration or less.

\subsection{Study Base}

Participants of this study were 1,304 males and 1,647 females (total 2,951) who joined the follow-up survey of the Tsuruoka Metabolomics Cohort Study between April 2015 and March 2016. Briefly, the Tsuruoka Metabolomics Cohort Study is a population-based study started in April 2012 in Tsuruoka City, Yamagata Prefecture, Japan. A total of 11,002 participants aged 35-74 years were recruited from municipal or worksite health check-ups in the city during the baseline period from 2012 to 2014 and enrolled. Follow-up surveys of this original cohort are conducted periodically. Participant information, including social factors, medical history and medications was obtained from standardized self-administered questionnaires with face-to- face interview during the health check-up. Other measurements (height, weight, blood pressure and laboratory data) were also collected during the check-up. All data were recorded using anonymized participant linkers. Details have been reported previously $[12,13,14,15]$.

The study was approved by the Medical Ethics Committee of the School of Medicine, Keio University, Tokyo, Japan (Approval No 20110264). All individual participants in this study provided written informed consent.

\subsection{Self-reported medication use}

All participants were asked to complete a standardized self-administered questionnaire which included the items listed below. The answers were checked twice by trained interviewers (including non-medical professionals) by face-to-face interview.

$\otimes$ Are you currently (at least once a week) taking any medications? (yes or no).

1. Medication for hypertension (yes or blank).

2. Medication for blood sugar level-lowering (diabetes) (yes or blank).

3. Medication for cholesterol-lowering (dyslipidemia) (yes or blank).

We defined participants who answered 'yes' to the first question as self-reported medication users and those who answered 'no' as non-users. Self-reported medication users who chose "Medication for hypertension", "Medication for blood sugar levellowering (diabetes)" or "Medication for cholesterol-lowering (dyslipidemia)" were defined as self-reported medication users against each disease.

In addition, nurses interviewed participants separately from the interviews described above with regard to their medical history, including hypertension, diabetes and dyslipidemia. We defined those who were under medical treatment as selfreported medication users.

\subsection{True medication use}


'True medication users' were determined using medical and pharmacy health insurance claims from October 2014 to March 2016 provided by Tsuruoka City. To define medication categories, we used the drug database in Japan $[16,17]$ and codes of the Anatomical Therapeutic Chemical (ATC) provided by World Health Organization (WHO) [18]. For some medications which did not have an ATC code, we assigned the closest minimum code based on medication category. We defined antihypertensive as follows: medications with an ATC code starting from $\mathrm{C02}$ or listed as a medication for hypertension in Japan (Supplementary Table 1). Medications for diabetes were as follows: medications with an ATC code starting from A10 or listed as a medication for diabetes in Japan (Supplementary Table 2). Medications for dyslipidemia were as follows: medications with an ATC code starting from C10 or listed as a medication for dyslipidemia in Japan (Supplementary Table 3).

As long-term prescriptions are allowed in Japan, even if the participants were not prescribed the medications during the survey month, they might take the medications which have been prescribed during the previous month. Therefore, we identified 'True medication users' by collecting data for medications during the same month as the participants answered the self-reported questionnaires and the previous five months. As a previous study observed that fixed time windows (the time period) shorter than 90 days are less sensitive [19], we used three- and six-month fixed time windows for analyses [7].

\subsection{Additional covariate data of sociodemographic information}

Marital status was classified as married if a participant answered 'yes' to the question 'Do you currently have a spouse? (even if not living together)'. If a participant answered 'no', they were classified as single, divorced or widowed. If a participant's last education status was an elementary school, junior high school or high school, we classified them as having 12 or fewer years of education years. If they had graduated from a technical college, junior college, university or graduate school, we classified them as having more than 12 years of education years. Job status was classified as 'currently working' if participants were not homemakers or unemployed. The information was collected at the baseline survey and updated at the follow-up survey if their status had changed.

\subsection{Statistical methods}

We analyzed 2,720 beneficiaries (1,200 males and 1,520 females) of $\mathrm{NHI}$ or Medical Care System for the Advanced Elderly in this study because data on Employees' Health Insurance beneficiaries was not available at this time. We evaluated the prevalence of medication use as determined by the standardized self-administered questionnaire and by the health insurance claims separately. To assess the validity of self-reported medication use, we used the health insurance claims as a standard. Sensitivity, specificity, and agreement were calculated with $95 \%$ confidence intervals ( $95 \% \mathrm{Cls}$ ). Sensitivity identifies the proportion of self-reported medication users among true medication users, while specificity identifies the proportion of non-users according to the questionnaire among non-users detected by the health insurance claims.

Agreement between self-reported medication use and the health insurance claims was calculated using the kappa statistics. The kappa statistics vary from 0 to 1 and are interpreted as follows: fair to poor $(<0.40)$, moderate $(0.41-0.60)$, substantial (0.61-0.80), and almost perfect $(>0.81)[20,21]$. Furthermore, we performed logistic regression analysis to examine potential determinants of discordance which affected sensitivity in each medication group, such as gender, age, marital status, education years and job status. Odds ratios (ORs) with $95 \%$ Cls were calculated. Multivariable logistic regression was performed in each medication group by adjusting for all potential determinants mentioned above. Subgroup analyses stratified by gender were also performed. All statistical analyses were performed using SAS 9.4 (SAS Institute Inc., Cary, NC).

\section{Results}

\subsection{Basic Characteristics}

Table 1 shows the characteristics of participants. Mean and standard deviation (SD) age was 66 years (8.0) in total, and 65 (7.9) in males and 64 (8.1) in females. A higher proportion of males were married, working or taking prescribed medications for hypertension or diabetes than females. No obvious difference was noted in education years. The most commonly 
prescribed medications were antihypertensives. With a three-month fixed time window, the proportion of participants who took antihypertensives was $35 \%$ (males $41 \%$ and females $31 \%$ ), versus dyslipidemia medications at $28 \%$ (males $23 \%$ and females $32 \%$ ) and diabetes medications at $8.0 \%$ (males $11 \%$ and females $6.0 \%$ ).

\subsection{Validity of self-reported medication use}

Validation was performed between self-reported and true medication use (Table 2). Although there were no obvious differences in sensitivity, specificity or kappa scores between three- and six-month fixed time windows, we used the threemonth fixed time window for the following analyses as it showed slightly higher sensitivity than the six-month window. Also, no obvious differences were observed between trained interviewers (including non-medical professionals) and nurses. Furthermore, we conducted the same analyses stratified by gender, but saw no obvious differences between the three- and six-month fixed time windows (data not shown).

The self-reported use of antihypertensives and diabetes medications predicted the true use with high sensitivity (three-month fixed time window, 0.95 for antihypertensives and 0.94 for diabetes medications; six-month fixed time window, 0.94 for antihypertensives and 0.92 for diabetes medications). In contrast, the self-reported use for dyslipidemia medications showed lower sensitivity (three-month fixed time window, 0.84; six-month fixed time window, 0.84) than those for the other medications. Specificity was all over 0.94 . Also, agreement of dyslipidemia medications was lower than those for the other medications, but still within the almost perfect kappa scores (three-month fixed time window, 0.82; six-month fixed time window, 0.83).

\subsection{Determinants of discordance}

Analyses of subgroups with the three-month fixed time window stratified by sociodemographic factors including gender, age, education years, marital status and job status are shown in Table 3. In the antihypertensives and diabetes medications groups, sensitivity and specificity were all over 0.90 and kappa scores were all over 0.84 regardless of sociodemographic factors. In contrast, in the dyslipidemia medications group, gender (males, 0.71; females, 0.92) and education years (over 12 years, $0.91 ; 12$ or fewer years; 0.83 ) were associated with sensitivity. The associations were still observed after multivariate adjustment for both gender $(\mathrm{OR}, 5.0 ; 95 \% \mathrm{Cl}, 3.2-7.7)$ and education years (OR, 0.46; 95\% Cl, 0.24-0.87) (Table 4). Next, we conducted the same subgroup analyses stratified by gender (Supplementary Tables 4, 5). Males showed sensitivity of greater than 0.68 regardless of sociodemographic factors. Specificity was more than 0.92 and kappa score was more than 0.71. In the dyslipidemia medications group, sensitivity was associated with education years (over 12 years, $0.84 ; 12$ or fewer years, 0.68) even after multivariable analysis (OR, 0.43; 95\% Cl, 0.19-0.96) (Supplementary Table 6). Females showed high sensitivity and specificity, with all over 0.91 , and kappa scores were more than 0.84 . No significant determinants of discordant self-reporting were observed in females (Supplementary Table 7).

\section{Discussion}

In this study, we found that self-reported medication use had high validity for predicting true medication use, and that sensitivity for dyslipidemia medication use was lower than those for the other lifestyle-related diseases. Our data provide convincing evidence that self-reported medication use for lifestyle-related diseases is a valid measure of true medication use, regardless of whether the interviewer was a medical professional or not. Moreover, potential individual determinants, such as gender and number of years of education, were related with discordance in self-reported medication use for dyslipidemia.

\subsection{Three- and six-month fixed time windows}

No obvious differences in results were observed between three- and six-month fixed time windows by gender or interviewer. Medications for lifestyle-related diseases often need to be taken on a regular basis for a long time, and are often prescribed 
in quantities for courses of three months duration or less. This might have led us to recount the same participants as in the three-month fixed time window even when we fixed the time window for six months.

A previous population-based study in Japan validated self-reported medication use for lifestyle-related disease in 54,712 participants using a three-month fixed time window for pharmacy health insurance claims [6]. Their reported sensitivities for antihypertensives (92.4\%) and dyslipidemia medications (86.2\%) were similar to our present results, but their sensitivity for diabetes medications (82.6\%) was lower. The reason for this discrepancy is likely due to the type of health insurance claims covered - their validation was done using health insurance claims for pharmacy only, whereas we used claims for both medicine and pharmacy, which provided for more accurate results. Dyslipidemia medication use showed lower sensitivity than the other medication uses in both our present and this previous study [6]. Awareness level of dyslipidemia is reported to be lower than that of other lifestyle-related diseases such as hypertension [22]. Self-recognition of health condition is also reported to affect sensitivity [10].

To our knowledge, our present paper is one of only a few population-based validation studies of self-reported medication use which have covered all of the participants' health insurance claims.

\subsection{Determinants of discordance of self-reported medication use}

We found that type of medication, gender and education years were associated with the accuracy of self-reported medication use. The sensitivity of participants using medication for dyslipidemia was lower than those for the other medications. Moreover, males with having 12 or fewer years of education years showed lower sensitivity than those with more than 12 years.

Although a number of population-based studies have reported the validity of self-reported medication use, few studies have explored the individual determinants of discordance for self-reported medication use [7, 9, 10]. A study from Scotland which validated self-reported medication use for cholesterol-lowering medications and antihypertensives in 9,043 participants [7] observed that sociodemographic information, including age, gender, education and marital status did not affect discordance for cholesterol-lowering medication use, but found that female sex and younger age were associated with increased discordance for antihypertensive use. Although we observed no association between sociodemographic information and discordance for antihypertensives, other studies which conducted validation by medication classification, such as betablocking agents and calcium channel blockers, reported that male sex and older age were associated with increased discordance $[9,10]$. Given the possibility that participants taking antihypertensives might use the agents for nonantihypertensive purposes, such as arrhythmia, further study by medication classifications is required.

A study from Finland which validated diabetes medication use in 7,625 participants [9] and a study from Ireland which validated diabetes medication and lipid-modifying agent use in 2,621 participants [10] reported that sociodemographic information did not affect the discordance of self-reported medication use, showing the same tendency as our present result for diabetes medication use. The reason only our study identified gender and education years as determinants of discordance for dyslipidemia medication use may be due to slight differences among studies in data collection. Whereas our study collected medication data for dyslipidemia medication, the Scottish study [7] collected data on cholesterol-lowering medications only, and did not include medications for hypertriglyceridemia or hypo HDL-cholesterolemia. The Irish study [10] collected data by asking participants about the medications they regularly took, and asked them to provide medication packages to ensure use of the medication correctly.

Although previous studies did not identify education status as a determinant of discordance for self-reported medication use for lifestyle-related disease, a few studies of antidepressant use reported that a lack of high education was associated with worse recall $[4,7,9]$. We assume that participants without high education might take the medications not knowing their efficacy, due to either a lack of knowledge, lack of interest in the treatment, or poor health awareness, particularly with regard to diseases with few or no symptoms, such as dyslipidemia.

\subsection{Study strengths and weaknesses}


Among its strengths, this study was conducted by linkage of population-based cohort data with both medical and pharmacy health insurance claims. Our use of information on prescribed medications dispensed from hospitals and pharmacies enabled us to draw accurate results.

Several limitations of our study also warrant mention. First, we covered only a part of participants in this study, namely beneficiaries of $\mathrm{NHI}$ and Medical Care System for the Advanced Elderly. Further study will be required for beneficiaries of Employees' Health Insurance, which include most participants aged younger than 65 years. Second, the health insurance claims data may be insufficient for participants who newly changed their coverage from Employees' Health Insurance to $\mathrm{NHI}$. This might have increased the number of false-positive results. Third, adherence to medication was not considered. Although we observed high validation for each medication, we do not know if the participants took the medications correctly as indicated. Finally, only medications for lifestyle-related diseases were validated. Further study will be needed with other medications.

\section{Conclusion}

In conclusion, we found that the self-reported medication use for lifestyle-related diseases was a valid measure of true medication use. Sensitivity for dyslipidemia medications was lower than those for the others. Dyslipidemia medication, gender and number of years of education were associated with discordance in self-reporting.

\section{Abbreviations}

NHI:National Health Insurance; ATC:Anatomical Therapeutic Chemical; WHO:World Health Organization; 95\% Cls:95\% confidence intervals; ORs:Odds ratios; SD:standard deviation.

\section{Declarations}

\section{¿Ethics approval and consent to participate}

The study was approved by the Medical Ethics Committee of the School of Medicine, Keio University, Tokyo, Japan (Approval No 20110264). All individual participants in this study provided written informed consent.

\section{$\square$ Consent for publication}

All individual participants in this study provided written informed consent.

\section{$\square$ Availability of data and materials}

The dataset used and analysed during the current study are available from the corresponding author on reasonable request.

\section{$\square$ Competing interests}

The authors declare that they have no competing interests.

\section{aFunding}

This study was supported in part by research funds from the Yamagata Prefectural Government and the city of Tsuruoka and by JSPS KAKENHI Grant Number JP 16H06277, JP18H06377, JP19K21458. The funding bodies had no role in the design of the study and collection, analysis, and interpretation of data and in writing the manuscript.

\section{$\square$ Authors' contribution}

MM designed the study and conducted data analysis, data interpretation, and the writing of the manuscript. 
SH, MI, SK, MS, AH, KK, AT, DS, TO and TT were responsible for the data and contributed to data interpretation.

SH and TT were responsible for the original Tsuruoka Metabolomics Cohort Study design.

All the authors contributed to the revision of the manuscript and approved the final version.

\section{\Acknowledgments}

The authors would like to acknowledge the contribution of Tsuruoka City for the use of health insurance claims.

\section{References}

[1] Catapano AL, Graham I, De Backer G, Wiklund O, Chapman MJ, Drexel H, et al. 2016 ESC/EAS Guidelines for the Management of Dyslipidaemias. Eur Heart J 2016;37:2999-3058.

[2] Grundy SM, Stone NJ, Bailey AL, Beam C, Birtcher KK, Blumenthal RS, et al. 2018

AHA/ACC/AACVPR/AAPA/ABC/ACPM/ADA/AGS/APhA/ASPC/NLA/PCNA Guideline on the Management of Blood Cholesterol: Executive Summary: A Report of the American College of Cardiology/American Heart Association Task Force on Clinical Practice Guidelines. J Am Coll Cardiol 2019;73:3168-209.

[3] Kinoshita M, Yokote K, Arai H, lida M, Ishigaki Y, Ishibashi S, et al. Japan Atherosclerosis Society (JAS) Guidelines for Prevention of Atherosclerotic Cardiovascular Diseases 2017. J Atheroscler Thromb 2018;25:846-984.

[4] Klungel OH, de Boer A, Paes AH, Herings RM, Seidell JC, Bakker A. Influence of question structure on the recall of selfreported drug use. J Clin Epidemiol 2000;53:273-7.

[5] Cotterchio M, Kreiger N, Darlington G, Steingart A. Comparison of self-reported and physician-reported antidepressant medication use. Ann Epidemiol 1999;9:283-9.

[6] Fujita M, Sato Y, Nagashima K, Takahashi S, Hata A. Validity assessment of self-reported medication use by comparing to pharmacy insurance claims. BMJ Open 2015;5:e009490,2015-009490.

[7] Hafferty JD, Campbell Al, Navrady LB, Adams MJ, Maclntyre D, Lawrie SM, et al. Self-reported medication use validated through record linkage to national prescribing data. J Clin Epidemiol 2018;94:132-42.

[8] Monster TB, Janssen WM, de Jong PE, de Jong-van den Berg LT, PREVEND Study Group Prevention of REnal and Vascular ENT Stage Disease. Pharmacy data in epidemiological studies: an easy to obtain and reliable tool. Pharmacoepidemiol Drug Saf 2002;11:379-84.

[9] Haapea M, Miettunen J, Lindeman S, Joukamaa M, Koponen H. Agreement between self-reported and pharmacy data on medication use in the Northern Finland 1966 Birth Cohort. Int J Methods Psychiatr Res 2010;19:88-96.

[10] Richardson K, Kenny RA, Peklar J, Bennett K. Agreement between patient interview data on prescription medication use and pharmacy records in those aged older than 50 years varied by therapeutic group and reporting of indicated health conditions. J Clin Epidemiol 2013;66:1308-16.

[11] Ministry of Health, Labour and Welfare. Available at https://www.mhlw.go.jp/english/ (Accessed August 28, 2019).

[12] Harada S, Takebayashi T, Kurihara A, Akiyama M, Suzuki A, Hatakeyama Y, et al. Metabolomic profiling reveals novel biomarkers of alcohol intake and alcohol-induced liver injury in community-dwelling men. Environ Health Prev Med 2016;21:18-26. 
[13] lida M, Harada S, Kurihara A, Fukai K, Kuwabara K, Sugiyama D, et al. Profiling of plasma metabolites in postmenopausal women with metabolic syndrome. Menopause 2016;23:749-58.

[14] Fukai K, Harada S, lida M, Kurihara A, Takeuchi A, Kuwabara K, et al. Metabolic Profiling of Total Physical Activity and Sedentary Behavior in Community-Dwelling Men. PLoS One 2016;11:e0164877.

[15] Harada S, Hirayama A, Chan Q, Kurihara A, Fukai K, lida M, et al. Reliability of plasma polar metabolite concentrations in a large-scale cohort study using capillary electrophoresis-mass spectrometry. PLoS One 2018;13:e0191230.

[16] Ministry of Health, Labour and Welfare. Various Information of Medical Fee. Iyakuhin master. Available at http://www.iryohoken.go.jp/shinryohoshu/downloadMenu/ (Accessed October 10, 2018).

[17] Takahisa. F and Y. Yazaki. Therapeutics Manual 2019. Igaku-shoin; 2019. [In Japanese].

[18] WHO. Guideline for ATC classification and DDD assignment 2018. Available at https://www.whocc.no/filearchive/publications/2018_guidelines_web.pdf (Accessed October 10, 2018).

[19] Lau HS, de Boer A, Beuning KS, Porsius A. Validation of pharmacy records in drug exposure assessment. J Clin Epidemiol 1997;50:619-25.

[20] Altman DG. Practical statistics for medical research. London: Chapman \& Hall; 1991.

[21] Landis JR, Koch GG. The measurement of observer agreement for categorical data. Biometrics 1977;33:159-74.

[22] Tanaka T, Okamura T, Yamagata Z, Takebayashi T, Tamura U, Kusaka Y, et al. Awareness and treatment of hypertension and hypercholesterolemia in Japanese workers: the High-risk and Population Strategy for Occupational Health Promotion (HIPOP-OHP) study. Hypertens Res 2007;30:921-8.

\section{Tables}




\begin{tabular}{|c|c|c|c|c|c|c|c|}
\hline & \multicolumn{2}{|l|}{ Total } & \multicolumn{2}{|c|}{ Males } & \multicolumn{2}{|c|}{ Females } & \multirow[t]{2}{*}{$\mathbf{p}^{\ddagger}$} \\
\hline & $\square$ & Dor SD & $\square$ & पor SD & $\square$ & Q or SD & \\
\hline प & 2720 & $100 \%$ & 1200 & $100 \%$ & 1520 & $100 \%$ & \\
\hline Age (years) ${ }^{\dagger}$ & 66 & 8.0 & 65 & 7.9 & 64 & 8.1 & 0.21 \\
\hline More than 12 years of education, Yes & 637 & $23 \%$ & 267 & $22 \%$ & 370 & $24 \%$ & 0.20 \\
\hline Married, Yes & 2315 & $85 \%$ & 1065 & $89 \%$ & 1250 & $82 \%$ & $<0.001$ \\
\hline Currently working, Yes & 1772 & $65 \%$ & 893 & $74 \%$ & 879 & $58 \%$ & $<0.001$ \\
\hline \multicolumn{8}{|c|}{ Medication prevalence according to self-report } \\
\hline Antihypertensive & 1019 & $37 \%$ & 511 & $43 \%$ & 508 & $33 \%$ & $<0.001$ \\
\hline Diabetes medication & 254 & $9.0 \%$ & 156 & $13 \%$ & 98 & $6.0 \%$ & $<0.001$ \\
\hline Dyslipidemia medication & 718 & $26 \%$ & 220 & $18 \%$ & 498 & $33 \%$ & $<0.001$ \\
\hline \multicolumn{8}{|l|}{ Three-month fixed time window } \\
\hline Antihypertensive & 965 & $35 \%$ & 495 & $41 \%$ & 470 & $31 \%$ & $<0.001$ \\
\hline Diabetes medication & 225 & $8.0 \%$ & 137 & $11 \%$ & 88 & $6.0 \%$ & $<0.001$ \\
\hline Dyslipidemia medication & 763 & $28 \%$ & 278 & $23 \%$ & 485 & $32 \%$ & $<0.001$ \\
\hline \multicolumn{8}{|l|}{ Six-month fixed time window } \\
\hline Antihypertensive & 981 & $36 \%$ & 500 & $42 \%$ & 481 & $32 \%$ & $<0.001$ \\
\hline Diabetes medication & 234 & $9.0 \%$ & 144 & $12 \%$ & 90 & $6.0 \%$ & $<0.001$ \\
\hline Dyslipidemia medication & 784 & $29 \%$ & 288 & $24 \%$ & 496 & $33 \%$ & $<0.001$ \\
\hline
\end{tabular}

${ }^{\dagger}$ Reported as mean (SD: standard deviation). ${ }^{\ddagger}$ Comparison of males and females using Student's t-test and the $\chi^{2}$ - test.

Abbreviation: 95\% Cl, 95\% confidence interval.

Abbreviation: $95 \% \mathrm{Cl}$, 95\% confidence interval.

Abbreviation: 95\% Cl, 95\% confidence interval. 
Table 2. Validity of self-reported medication use.

Three-month fixed time window

$\begin{array}{lll}\text { Antihypertensive } & \begin{array}{l}\text { Diabetes } \\ \text { medication }\end{array} & \begin{array}{l}\text { Dyslipidemia } \\ \text { medication }\end{array}\end{array}$

\section{Six-month fixed time window}

Antihypertensive Diabetes medication
Dyslipidemia medication

\section{Trained \\ interviewers \\ (includingnon- \\ medical \\ professionals)}

True-positive,

True-positive, 915

$\mathrm{N}$

True-negative, 1651

$\mathrm{N}$

False-positive, 104

$\mathrm{N}$

False-

negative, $\mathrm{N}$

Sensitivity

50

14

211

644

924

216

659

$(95 \rrbracket \mathrm{Cl})$

0.95(0.93-0.96)

2452

1883

1644

2448

1877

Specificity

43

74

95

38

59

$(95 \rrbracket \mathrm{Cl})$

$0.94(0.93-0.95)$

$0.94(0.91$

0.97 )

119

57

18

125

Kappa score

(95区 Cl)

$0.88(0.86-0.90)$

0.98(0.98-

0.99)

0.84(0.82-

0.87 )

0.94(0.93-0.96)

0.92(0.89-

$0.96)$

$0.84(0.81-$

$0.87)$

\section{Nurses}

True-positive, 903

$\begin{array}{ll}0.87(0.84- & 0.82(0.80- \\ 0.90) & 0.85)\end{array}$

0.96(0.95-

$0.97)$

0.95(0.93-0.96)

0.98(0.98-

0.99 )

0.97(0.96-

0.98)

$\mathrm{N}$

$\mathrm{T}$

True-negative, 1457

$0.90)$

$0.85)$

$0.88(0.86-0.90)$

0.87(0.84-

0.91 )

$0.83(0.81-$

$0.85)$

False-positive, 42

$\mathrm{N}$

False-

58

212

632

907

213

641

negative, $\mathrm{N}$

2200

1666

1449

2195

1659

Sensitivity

(95区 Cl)

0.94(0.92-0.95)

36

33

38

35

24

Specificity

(95区 Cl)

$0.97(0.96-0.98)$

12

129

66

17

136

Kappa score

(95区 Cl)

0.91(0.90-0.93)

0.95(0.92-

$0.98)$

0.83(0.80-

$0.86)$

$0.93(0.92-0.95)$

$0.93(0.89$

0.96)

$0.82(0.80-$

0.98(0.98- $\quad 0.98(0.97-$

0.99)

0.99)

0.97(0.97-0.98)

0.98(0.98-

0.99)

$0.85)$

$0.89(0.86-\quad 0.84(0.82-$

0.92)

0.86)

0.91(0.89-0.93)

0.88(0.85-

$0.91)$

0.99(0.98-

0.99)

$0.84(0.82-$

$0.87)$ 
Table 3. Validity of self-reported medication use among subgroups with a three-month fixed time window.

$\begin{array}{ll}\text { Gender } \quad \text { Age } & \begin{array}{l}\text { More than } 12 \text { years } \\ \text { education }\end{array}\end{array}$

\begin{tabular}{|c|c|c|c|c|c|c|}
\hline & Males & Females & $65-78$ years & $35-64$ years & Yes & No \\
\hline \multicolumn{7}{|l|}{ Antihypertensive } \\
\hline True-positive, N & 467 & 448 & 669 & 246 & 171 & 741 \\
\hline True-negative, $\mathrm{N}$ & 661 & 990 & 806 & 845 & 435 & 1207 \\
\hline False-positive, N & 44 & 60 & 66 & 38 & 29 & 74 \\
\hline False-negative, N & 28 & 22 & 40 & 10 & 2 & 47 \\
\hline Sensitivity $(95 \rrbracket \mathrm{Cl})$ & $\begin{array}{l}0.94(0.92- \\
0.96)\end{array}$ & $\begin{array}{l}0.95(0.93- \\
0.97)\end{array}$ & $\begin{array}{l}0.94(0.93- \\
0.96)\end{array}$ & $\begin{array}{l}0.96(0.94- \\
0.98)\end{array}$ & $\begin{array}{l}0.99(0.97- \\
1.0)\end{array}$ & $\begin{array}{l}0.94(0.92- \\
0.96)\end{array}$ \\
\hline Specificity $(95 \rrbracket \mathrm{Cl})$ & $\begin{array}{l}0.94(0.92- \\
0.96)\end{array}$ & $\begin{array}{l}0.94(0.93- \\
0.96)\end{array}$ & $\begin{array}{l}0.92(0.91- \\
0.94)\end{array}$ & $\begin{array}{l}0.96(0.94- \\
0.97)\end{array}$ & $\begin{array}{l}0.94(0.92- \\
0.96)\end{array}$ & $\begin{array}{l}0.94(0.93- \\
0.96)\end{array}$ \\
\hline $\begin{array}{l}\text { Kappa score (95区 } \\
\text { Cl) }\end{array}$ & $\begin{array}{l}0.88(0.85- \\
0.90)\end{array}$ & $\begin{array}{l}0.88(0.85- \\
0.90)\end{array}$ & $\begin{array}{l}0.86(0.84- \\
0.89)\end{array}$ & $\begin{array}{l}0.88(0.85- \\
0.92)\end{array}$ & $\begin{array}{l}0.88(0.84- \\
0.92)\end{array}$ & $\begin{array}{l}0.88(0.86- \\
0.90)\end{array}$ \\
\hline
\end{tabular}

\section{Diabetes medication}

\begin{tabular}{|c|c|c|c|c|c|c|}
\hline True-positive, N & 126 & 85 & 150 & 61 & 28 & 180 \\
\hline True-negative, $\mathrm{N}$ & 1033 & 1419 & 1390 & 1062 & 600 & 1842 \\
\hline False-positive, N & 30 & 13 & 31 & 12 & 6 & 36 \\
\hline False-negative, N & 11 & 3 & 10 & 4 & 3 & 11 \\
\hline Sensitivity $(95 \rrbracket \mathrm{Cl})$ & $\begin{array}{l}0.92(0.87- \\
0.97)\end{array}$ & $\begin{array}{l}0.97(0.93- \\
1.0)\end{array}$ & $\begin{array}{l}0.94(0.90- \\
0.98)\end{array}$ & $\begin{array}{l}0.94(0.88- \\
1.0)\end{array}$ & $\begin{array}{l}0.90(0.80- \\
1.0)\end{array}$ & $\begin{array}{l}0.94(0.91- \\
0.98)\end{array}$ \\
\hline Specificity $(95 \rrbracket \mathrm{Cl})$ & $\begin{array}{l}0.97(0.96- \\
0.98)\end{array}$ & $\begin{array}{l}0.99(0.99- \\
1.0)\end{array}$ & $\begin{array}{l}0.98(0.97- \\
0.99)\end{array}$ & $\begin{array}{l}0.99(0.98- \\
1.0)\end{array}$ & $\begin{array}{l}0.99(0.98- \\
1.0)\end{array}$ & $\begin{array}{l}0.98(0.97- \\
0.99)\end{array}$ \\
\hline $\begin{array}{l}\text { Kappa score (958 } \\
\text { Cl) }\end{array}$ & $\begin{array}{l}0.84(0.79- \\
0.89)\end{array}$ & $\begin{array}{l}0.91(0.86- \\
0.95)\end{array}$ & $\begin{array}{l}0.87(0.82- \\
0.91)\end{array}$ & $\begin{array}{l}0.88(0.82- \\
0.94)\end{array}$ & $\begin{array}{l}0.85(0.76- \\
0.95)\end{array}$ & $\begin{array}{l}0.87(0.84- \\
0.91)\end{array}$ \\
\hline \multicolumn{7}{|l|}{$\begin{array}{l}\text { Dyslipidemia } \\
\text { medication }\end{array}$} \\
\hline True-positive, N & 197 & 447 & 471 & 173 & 123 & 518 \\
\hline True-negative, $\mathrm{N}$ & 899 & 984 & 979 & 904 & 475 & 1398 \\
\hline False-positive, $\mathrm{N}$ & 23 & 51 & 42 & 32 & 27 & 46 \\
\hline False-negative, $\mathrm{N}$ & 81 & 38 & 89 & 30 & 12 & 107 \\
\hline Sensitivity $(95 \rrbracket \mathrm{Cl})$ & $\begin{array}{l}0.71(0.66- \\
0.76)\end{array}$ & $\begin{array}{l}0.92(0.90- \\
0.95)\end{array}$ & $\begin{array}{l}0.84(0.81- \\
0.87)\end{array}$ & $\begin{array}{l}0.85(0.80- \\
0.90)\end{array}$ & $\begin{array}{l}0.91(0.86- \\
0.96)\end{array}$ & $\begin{array}{l}0.83(0.80- \\
0.86)\end{array}$ \\
\hline Specificity (95区 Cl) & $\begin{array}{l}0.98(0.96- \\
0.99)\end{array}$ & $\begin{array}{l}0.95(0.94- \\
0.96)\end{array}$ & $\begin{array}{l}0.96(0.95- \\
0.97)\end{array}$ & $\begin{array}{l}0.97(0.95- \\
0.98)\end{array}$ & $\begin{array}{l}0.95(0.93- \\
0.97)\end{array}$ & $\begin{array}{l}0.97(0.96- \\
0.98)\end{array}$ \\
\hline $\begin{array}{l}\text { Kappa score } \\
(95 \rrbracket \mathrm{Cl})\end{array}$ & $\begin{array}{l}0.74(0.69- \\
0.78)\end{array}$ & $\begin{array}{l}0.87(0.84- \\
0.89)\end{array}$ & $\begin{array}{l}0.82(0.79- \\
0.85)\end{array}$ & $\begin{array}{l}0.8(0.77- \\
0.86)\end{array}$ & $\begin{array}{l}0.82(0.77- \\
0.88)\end{array}$ & $\begin{array}{l}0.82(0.79- \\
0.85)\end{array}$ \\
\hline
\end{tabular}




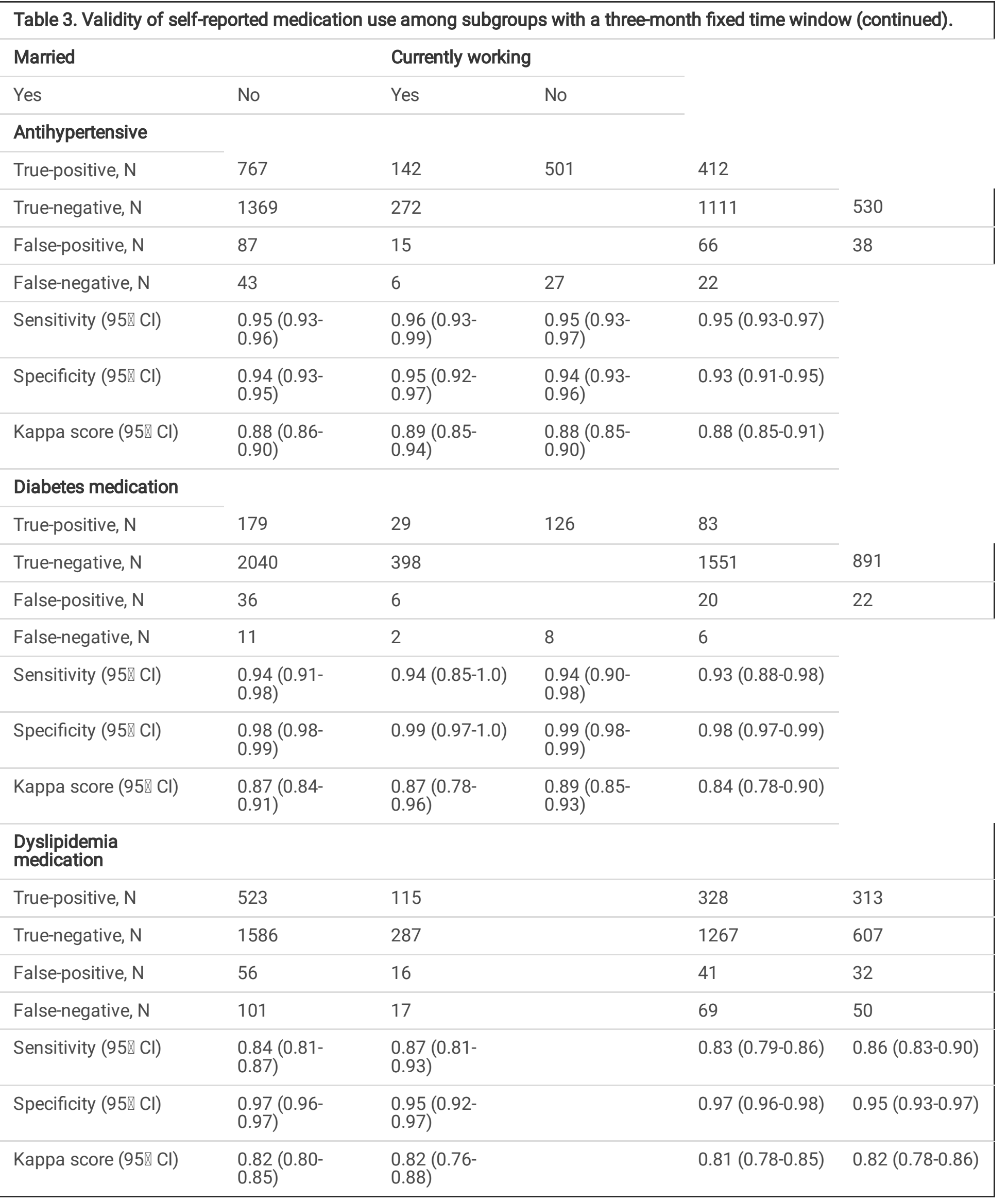




\begin{tabular}{|c|c|c|c|c|}
\hline & \multicolumn{4}{|c|}{ Antihypertensive } \\
\hline & OR[Crude] & $95 \square \mathrm{Cl}$ & OR[Adjusted] & $95 \square \mathrm{Cl}$ \\
\hline Gender & 1.2 & $(0.69-2.2)$ & 1.2 & $(0.66-2.2)$ \\
\hline Age & 1.5 & $(0.72-3.0)$ & 1.5 & $(0.71-3.3)$ \\
\hline Education years & 0.18 & $(0.04-0.77)$ & 0.20 & $(0.05-0.82)$ \\
\hline Marital status & 1.3 & $(0.55-3.2)$ & 1.5 & $(0.57-3.9)$ \\
\hline \multirow[t]{3}{*}{ Job status } & 1.0 & $(0.57-1.8)$ & 1.1 & $(0.59-2.0)$ \\
\hline & \multicolumn{4}{|c|}{ Diabetes medication } \\
\hline & OR[Crude] & $95 \square \mathrm{Cl}$ & OR[Adjusted] & $95 \square \mathrm{Cl}$ \\
\hline Gender & 2.5 & $(0.67-9.1)$ & 2.3 & $(0.60-9.1)$ \\
\hline Age & 1.0 & $(0.31-3.4)$ & 1.1 & $(0.29-3.9)$ \\
\hline Education years & 1.8 & $(0.46-6.7)$ & 1.9 & $(0.47-7.5)$ \\
\hline Marital status & 0.89 & $(0.19-4.2)$ & 0.64 & $(0.13-3.2)$ \\
\hline \multirow[t]{3}{*}{ Job status } & 0.88 & $(0.29-2.6)$ & 1.1 & $(0.32-3.6)$ \\
\hline & \multicolumn{4}{|c|}{ Dyslipidemia medication } \\
\hline & OR[Crude] & $95 \square \mathrm{Cl}$ & OR[Adjusted] & $95 \square \mathrm{Cl}$ \\
\hline Gender & 4.8 & $(3.2-7.4)$ & 5.0 & $(3.2-7.7)$ \\
\hline Age & 1.1 & $(0.70-1.7)$ & 1.2 & $(0.72-1.9)$ \\
\hline Education years & 0.47 & $(0.25-0.89)$ & 0.46 & $(0.24-0.87)$ \\
\hline Marital status & 1.3 & $(0.75-2.3)$ & 0.90 & $(0.50-1.6)$ \\
\hline Job status & 1.3 & $(0.89-2.0)$ & 1.0 & $(0.67-1.6)$ \\
\hline
\end{tabular}

Abbreviation: OR, odds ratio. $95 \% \mathrm{Cl}, 95 \%$ confidence interval. The following factors were used as controls: female sex, 35-64 years, 12 or fewer years of education years, no marital status and not currently working.

\section{Supplementary Files}

This is a list of supplementary files associated with this preprint. Click to download.

- BMCsupplementary.docx 